\title{
Identification of Novel Drug Leads for Receptors Implicated in Migraine from Traditional Ayurvedic Herbs Using in silico and in vitro Methods
}

\author{
Preenon Bagchi ${ }^{1,3,5 *}$, Venkatramana $\mathrm{DK}^{2}$, Mahesh $\mathbf{M}^{1,5}$, Somashekhar $\mathbf{R}^{1,3,5}$ and Ajit Kar ${ }^{4,5}$ \\ ${ }^{1}$ Azyme Biosciences Pvt. Ltd., Bangalore, Karnataka, 560069, India \\ ${ }^{2}$ Bhat Biotech India Pvt. Ltd., Bangalore, Karnataka 560100, India \\ ${ }^{3}$ Career Point University, Kota, Rajasthan 324005, India \\ ${ }^{4}$ Satsang Herbal Research Laboratory, Satsang, Deoghar, Jharkhand 814116, India \\ ${ }^{5}$ Sarvasumana Association, Bangalore, Karnataka, 560069, India
}

\begin{abstract}
Background: Migraine is a chronic neurological disorder characterized by headaches along with several physiological and autonomic nervous system symptoms. Research suggests that migraine is a result of multi-gene mutation in combination with psycho-social and environmental factors.

Method: Mutated mammalian serotonin hydroxytryptamine receptor 2 (HTR2) implicated as factor causing migraine were retrieved from the National Centre for Biotechnology Information (NCBI), its 3D structure were determined by homology modelling. The 3D structures of phyto-compounds (from Ayurvedic herbs) were retrieved from various databases. The pharmacophore hypothesis was generated for the existing ligands and the phytocompounds were screened against the generated pharmocophoric hypothesis. Ligands were shortlisted based on their fitness score. The selected phytocompounds were screened against HTR2 receptor.
\end{abstract}

Results: The phytocompound having the best docking score and most interactions with the receptor are validated using receptor-ligand binding assay studies with HTR2 receptor in-vitro.

Conclusion: Phytocompounds selected as per receptor-ligand binding assay studies.

Keywords: Migraine; Serotonin; Ayurveda; Modeling; Pharmacophore; Docking; Rapid eye movement (REM); Binding assay

\section{Background}

The current manuscript is a continuation work of manuscript titled "Selecting the best ligand for Migraine Protein 5-hydroxytryptamine (serotonin) receptor 2A (HT2A) from the Compounds of Valeriana wallichii, Asparagus racemosus and Acorus calamus" by Somashekhar R, Bagchi P et al., 2014.

Rapid eye movement sleep behavior disorder (RBD) is a sleep disorder that involves abnormal behaviour during rapid eye movement (REM) sleep [1]. REM is the stage of sleep during which most vibrant dreaming occurs. The loss of motor inhibition leads to a wide spectrum of behavior during sleep. Migraine is a type of REM disorder [2]. Studies suggest that genetics, prenatal care with environment, combined with psychological and social factors are important causes of migraine. Research suggests that migraine is caused by actions of several mutated genes [3]. Migraine is the most frequent neurological disorder in the adult population worldwide. Headache is the primary clinical symptom and it has been associated with a hereditary or dependence of neurovascular reactions to cyclic changes in the central nervous system. Amongst the many neurotransmitters in the brain, the serotonergic (serotonin, 5-HT) system from the brainstem raphe nucleus has been most believably implicated in migraine pathophysiology [4]. The mammalian HT2 receptor is the main excitatory receptor subtype among the (G protein-coupled receptor) GPCRs for serotonin. HTR2 may also have an inhibitory effect $[5,6]$ on certain areas such as the visual cortex and the orbitofrontal cortex. Serotonin (5-hydroxytryptamine $(5-\mathrm{HT}) 1)$ is a major neurotransmitter that is involved in multiple physiological functions such as the control of endocrine secretion, motor behavior, mood, pain, sleep, thermoregulation, and appetite and is indicated as causal factor for several allied neuronal disorders $[7,8]$.

Mutation in mammalian serotonin hydroxytryptamine receptor 2 (HTR2), implicated as factors causing migraine, is taken in this study
$[3,4]$. The use of phytochemicals as novel, potential lead drug molecules for HTR2, a GPC receptor was tested in silico and in vitro in this study by matching the pharmacophoric features of a known ligand myristicin with the phytocompounds from Ayurvedic herbs (The psychotropic property of the herbs used in this work are based on practical studies carried out at Satsang Herbal Research Laboratory, Satsang, Deoghar, India) (Table 1). Myristicin is an agonist pertaining to HTR2 receptor [9]. It is a natural product isolated from parsley oil [10]. This volatile oil, myristicin, comprises a mixture of allylbenzene derivatives and terpines [11]

\section{Methodology}

\section{Predicting the 3D structure of the receptors}

The amino acid sequence of the HTR2 receptor was retrieved from the National Center for Biotechnology Information (NCBI). Using Basic Local Alignment and Search Tool (BLAST) search engine against Protein Data Bank (PDB) the homologous templates for the receptor was selected and their crystal structure was downloaded from PDB. Using these homologous templates, the $3 \mathrm{D}$ structure of the receptor was generated by modeler [12].

*Corresponding author: Preenon Bagchi, Azyme Biosciences Pvt. Ltd., Bangalore Karnataka, 560069, India, Tel: 00919886274603; E-mail: preenonb@yahoo.com

Received August 06, 2014; Accepted October 19, 2014; Published October 21, 2014

Citation: Bagchi P, Venkatramana DK, Mahesh M, Somashekhar R, Kar A (2014) Identification of Novel Drug Leads for Receptors Implicated in Migraine from Traditional Ayurvedic Herbs Using in silico and in vitro Methods. J Neurol Disord 2 185. doi:10.4172/2329-6895.1000185

Copyright: @ 2014 Bagchi $P$, et al. This is an open-access article distributed under the terms of the Creative Commons Attribution License, which permits unrestricted use, distribution, and reproduction in any medium, provided the original author and source are credited. 
Citation: Bagchi P, Venkatramana DK, Mahesh M, Somashekhar R, Kar A (2014) Identification of Novel Drug Leads for Receptors Implicated in Migraine from Traditional Ayurvedic Herbs Using in silico and in vitro Methods. J Neurol Disord 2: 185. doi:10.4172/2329-6895.1000185

Page 2 of 8

\begin{tabular}{|c|c|c|c|}
\hline 3-O-Acetyl-a-boswellic acid & Phyllanthin & Rubiadin & Corosolic acid \\
\hline Demethoxycurcumin & Eupalitin & 18a-Glycrrhetinic acid & 3,3',4,4'-Tetraahydroxy-2-Methoxychalcone \\
\hline Lutein & Asiaticoside & Berberine chloride dihydrate & \\
\hline 14-Deoxy-11,12-didehydroandrographolide & Picroside I & Rutin & Hypophyllanthin \\
\hline Mangiferin & Eupalitin-3-O-galactoside & 18a-Glycrrhetinic acid & Crocetin dialdehyde \\
\hline 3-O-Acetyl-11-keto- $\beta$-boswellic acid & Agnuside & Bisdemethoxycurcumin & Ursolic acid \\
\hline 1,9-Dideoxyforskolin & Picroside II & Serratol & 4-Hydroxyisoleucine \\
\hline Marmelosin & Eclalbasaponin II & Glcyrrihizin ammonical hydrate & Curcumin \\
\hline 3-O-Acetyl- $\beta$-boswellic acid & Allylpyrocatechol 3,4 diacetate & Boeravinone B & Vasicinone \\
\hline Diosgenin & Piperine & Sesamin & 3'-Hydroxy,4'-methoxyglabridin \\
\hline Methylgallate & Eicosyl caffeate & Guggulsterone & Caffeine \\
\hline Apocynin & trans-Anethole & A-Boswellic acid & Vicine \\
\hline Docosyl caffeate & $\begin{array}{l}\text { Protocatechuic acid ( } 3,4 \\
\text { dihydroxybenzoic acid) }\end{array}$ & Ahatavarin IV & Isoforskolin \\
\hline Methyl eugenol & Epocatechin & Gymnemagenin & Campesterol \\
\hline 1'-Acetoxychavicol acetate & Aristolochic acid 1 & Betaine & Vasicine \\
\hline 2',3'-Dehydrosalannol & Estragole & $\beta$-Sitesterol & Isoeugenol \\
\hline 3-O-Methylellagic acid & Artemisinin & $\beta$-Glucogallin & Capsaicin \\
\hline 4-Allylpyrocatechol & Psoralen & Betulinic acid & Vanillylacetone \\
\hline 7-O-Methylwogonin & Ferulic acid & Galangin & Isoformononetin \\
\hline 3,3'-Di-o-methyl ellagic acid & Atlantone & Caffeic acid & Caryophyllene \\
\hline \multirow[t]{2}{*}{ 4'-O- $\beta$-D-Andrographolide } & Punicalagin $(\alpha+\beta)$ & Stigmasterol & Wedelolactone \\
\hline & Forskolin & Geraniol & Jujubogenin isomer of bacopasaponin C \\
\hline Maslinic acid & Bacopasaponin C & Catechin & Bacopasaponin C \\
\hline xylopyranoside & Pterostilbene & Stevioside & Cedrol \\
\hline Andrograpanin & Furanoeudesma-1,3-diene & Geranyl acetate & Withanolide A \\
\hline Methanol & Bacopaside II & Catechin-5-O-gallate & Kaempferol \\
\hline I Deoxynojirimycin & Pyrogallol & Tetrahydrocurcumin & Chrysophanol \\
\hline Apigenin & Formononetin & Harmalin & Withaferin A \\
\hline Menthyl acetate & Bacopaside I & Chebulagic acid & 11-keto- $\beta$-boswellic acid \\
\hline Elemonic acid $(\alpha+\beta)$ & Piperyline & Trigonelline $\mathrm{HCl}$ & 1,8-Cineole \\
\hline Arjunetin & Gallic acid & Harmalol & Withanolide B \\
\hline Neandrographolide & Bacoside A3 & Chebulinic acid & L-Dopa \\
\hline Elemonic acid $(\beta)$ & Quercetin dihydrate & 1,3,6-Trigalloyl- $\beta$-D-glucose & Cirsilineol \\
\hline Arjunic acid & 6-Gingerol & Harmine & Withanone \\
\hline Negundoside & Bacoside A & Chlorogenic acid & Lupeol \\
\hline Arjungenin & Rebaudioside A & Tribulosin & Cinnamic acid \\
\hline Ellagic acid & 8-Gingerol & Hexahydrocurcumin & Withanoside IV \\
\hline Oleanolic acid & Bacosine & Colchicine & Luteolin \\
\hline ar-Turmerone & Reserpine & Trigoneoside IV a & m-Coumaric acid \\
\hline Embelin & 10-Gingerol & Hydroxycitric acid Calcium & Withanoside V \\
\hline 1-Octacosanol & Bakuchicin & Salt & Licochalcone A \\
\hline Eugenol & Rosamarinic acid & Corilagin & Deacylgymnemic acid \\
\hline a-Asarone & Glabridin & $3 \beta$-Taxaxerol & 12-Deoxywithastramonolide \\
\hline Panduratin-A & Bakuchiol & Hydroxycitric acid lactone & Lycopene \\
\hline Epocatechin-3-gallate & Para methoxyethylcinnamte & Epigallocatechin 3-gallate & Asiatic acid \\
\hline \multicolumn{4}{|l|}{ a-Asarone } \\
\hline & Source: Natura & lies, Bangalore, India. & \\
\hline
\end{tabular}

Table 1: List of phyto-compounds from traditional ayurvedic herbs.

\section{Model quality assessment}

Modeller [12] generated five models. Using Structural Analysis and Verification Server (SAVES)'s PROCHECK Module, (this stereochemical check was applied to verify if the $\varphi$ and $\psi$ dihedral angles were in available regions of the Ramachandran plot) the best protein model was selected [13].

\section{Phyto-compounds from traditional ayurvedic herbs}

\section{Ligand preparation}

The $3 \mathrm{~d}$ structures of the above phyto-compounds were downloaded from PubChem, a database of chemical molecules maintained by the NCBI and various other online databases.

\section{Generating phase database}

Now using Application $\rightarrow$ Phase $\rightarrow$ Generate Phase Database module of Maestro software phase database of the phyto-compounds was done [14].

\section{Selection of ligands for HTR2 receptor}

Ligand-based pharmacophore model was selected by extracting the common features of the three-dimensional structures of compounds 
Citation: Bagchi P, Venkatramana DK, Mahesh M, Somashekhar R, Kar A (2014) Identification of Novel Drug Leads for Receptors Implicated in Migraine from Traditional Ayurvedic Herbs Using in silico and in vitro Methods. J Neurol Disord 2: 185. doi:10.4172/2329-6895.1000185

Page 3 of 8

which are known to interact with the target protein (known ligand). Known ligands were loaded in the Maestro workspace and by using Applications $\rightarrow$ Phase $\rightarrow$ Create Hypothesis module pharmacophore features of the known ligands were noted [14].

\section{Docking}

Protein preparation: The modeler generated protein is not suitable for immediate use in docking or other molecular modeling calculations. By using Protein Preparation Wizard of Maestro9.1 the modeler generated protein was uploaded for optimization and energy minimization [14].

Binding site generation: The binding site position of the protein was determined by SiteMap module of Maestro [14].

Ligand preparation: The ligands were selected in Maestro workspace. Using ligprep, the ligands were minimised prepared for docking studies. LigPrep is tool to prepare high quality 3D structure for large number of molecules taking input as $2 \mathrm{D}$ or $3 \mathrm{D}$ structures and giving output as a single, low energy 3D structure [14].

Receptor grid generation: The receptor was loaded in workspace. Using Glide $\rightarrow$ Receptor Grid Generation the binding site region of the receptor was specified and the receptor was prepared for docking.

Glide docking: Using module Glide $\rightarrow$ Ligand Docking module of Maestro the receptor was docked with the selected ligands [14].

\section{ADME screening}

ADME is an acronym in pharmacokinetics and pharmacology for absorption, distribution, metabolism, and excretion. Using QikProp module the ADME properties of the above ligands was determined [14].

\section{Generation of stable cell line expressing HTR2}

Synthetic HTR2 gene (Geneart, Germany) was cloned into pcDNA3.1 vector (Invitrogen) between BamHI and XbaI sites. Clones were confirmed by sequencing. Human Embryonic Kidney (HEK 293) cell line (National Centre for Cell Sciences, Pune, India) were transfected with pcDNA3.1-HTR2 and grown in the presence of $1 \mathrm{mg} /$ $\mathrm{ml}$ Geneticin (G418).Cells resistant to $1 \mathrm{mg} / \mathrm{ml} \mathrm{G} 418$ were selected, expanded and used for receptor ligand binding assay. The expression of HTR2 in stable cell line was confirmed by RT-PCR using specific primers.

\section{Receptor-ligand binding assay studies}

Binding efficacy of the phytocompounds colchicine and hypophyllanthanthin with the HTR2 receptor was tested in-vitro by measuring agonist stimulated calcium signalling using Fluo-4 Direct calcium assay kit (Invitrogen).5HT (Sigma), a known agonist of HTR2 was used as positive control for the test. $1 \times 10^{4}$ cells in $50 \mu \mathrm{l}$ of DMEM (Dulbekos Modified Eagle's Medium)-10\% FBS (Fetal Bovine Serum) were seeded in 96 well tissue culture plate and grown overnight at $37^{\circ} \mathrm{C} / 5 \% \mathrm{CO}_{2}$ in humidified incubator. $50 \mu \mathrm{l}$ of $2 \mathrm{X}$ Fluo- 4 direct calcium reagent loading solution was added and incubated for 60 seconds at $37^{\circ} \mathrm{C}$. Different concentrations of agonist were added in duplicate wells and incubated for 4 hours at $37^{\circ} \mathrm{C}$. Fluorescence was measured with excitation at $494 \mathrm{~nm}$ and emission at $516 \mathrm{~nm}$ using Flurometer.

\section{Results and Discussion}

The HTR2 receptor was selected from the NCBI database (Table 2). The 3D structure of HTR2 receptor was modelled by Modeller [12].

\begin{tabular}{|l|l|l|}
\hline $\begin{array}{l}\text { Protein \& NCBI } \\
\text { Accession Number }\end{array}$ & Homologous Templates & Identity \\
\hline HTR2 (NP_001159419) & $\begin{array}{l}\text { 2VT4A: Turkey Beta1 Adrenergic } \\
\text { Receptor With Stabilising Mutations And } \\
\text { Bound Cyanopindolol } \\
\text { 2YOOA: Turkey Beta1 Adrenergic } \\
\text { Receptor With Stabilising Mutations And } \\
\text { Bound Partial Agonist Dobutamine } \\
\text { 3SN6A: Crystal Structure Of The } \\
\text { Beta2 Adrenergic Receptor-Gs Protein } \\
\text { Complex E-value-2e-26 }\end{array}$ & \\
\hline
\end{tabular}

Table 2: Proteins with the NCBI accession number and their template information

\begin{tabular}{|l|l|l|l|l|}
\hline & $\begin{array}{l}\text { Number of } \\
\text { residues in } \\
\text { most favoured } \\
\text { region }\end{array}$ & $\begin{array}{l}\text { Number of } \\
\text { residues in } \\
\text { additional } \\
\text { allowed region }\end{array}$ & $\begin{array}{l}\text { Number of } \\
\text { residues in } \\
\text { generously } \\
\text { allowed region }\end{array}$ & $\begin{array}{l}\text { Number of } \\
\text { residues in } \\
\text { dis-allowed } \\
\text { region }\end{array}$ \\
\hline Model 1 & $314(88.0 \%)$ & $33(9.2 \%)$ & $7(2.0 \%)$ & $3(0.8 \%)$ \\
\hline Model 2 & $319(89.4 \%)$ & $32(9.0 \%)$ & $4(1.1 \%)$ & $2(0.6 \%)$ \\
\hline Model 3 & $331(92.7 \%)$ & $19(5.3 \%)$ & $2(0.6 \%)$ & $5(1.4 \%)$ (selected) \\
\hline Model 4 & $319(89.4 \%)$ & $31(8.7 \%)$ & $2(0.6 \%)$ & $5(1.4 \%)$ \\
\hline Model 5 & $328(91.9 \%)$ & $20(5.6 \%)$ & $3(0.8 \%)$ & $6(1.7 \%)$ \\
\hline
\end{tabular}

Table 3: Values of 5HT2A protein obtained in favoured, allowed and disallowed region using Ramachandran Plot (SAVES server).

\begin{tabular}{|l|l|l|}
\hline Identified ligands & Fitness score & Plant \\
\hline Colchicine & 2.121 & Colchicum autumnale \\
\hline Hypophyllanthanthin & 1.713 & Phyllanthus amarus \\
\hline
\end{tabular}

Table 4: Ligands which matches with the pharmacophore of Myristicin and their fitness score.

\section{Predicting the 3D structure of HTR2 receptor}

The $3 \mathrm{~d}$ structure of HTR2 receptor was modeled since the crystal structure of HTR2 receptor was not available in the PDB. Using BLAST search against PDB templates or homologous proteins related to HTR2 were selected.

This best aligned template is taken for homology modeling studies by using modeler (Table 2). Ramachandran plot analysis of the best generated model gave $92.7 \%$ residues in the core region, $5.3 \%$ in allowed region, $0.6 \%$ in generously allowed region and $1.4 \%$ disallowed region (Table 3, Figures 1 and 2). This model was selected as the best model since it had most residues in the favoured region.

The three dimensional structure provides valuable insight into molecular function and also enables the protein-protein interaction to be analyzed.

\section{Pharmacophore studies}

Ligand-based pharmacophore models are selected by extracting the common features of the three-dimensional structures of the known ligands. To do this, possible conformers of compounds should be previously enumerated.

Then, we superpose our target compounds by overlapping the three-dimensional structures' common substructures as molecular graphs among the other parts of compounds. So, in this method, since we do not have to enumerate all the conformers of a compound, we usually save much computational time by ligand-based pharmacophore modeling [15].

The pharmacophore features of all known 5-HT ligands, were generated but none (except myristicin) of the phytocompounds showed any common feature with the pharmacophore of the known 5HT ligands. 

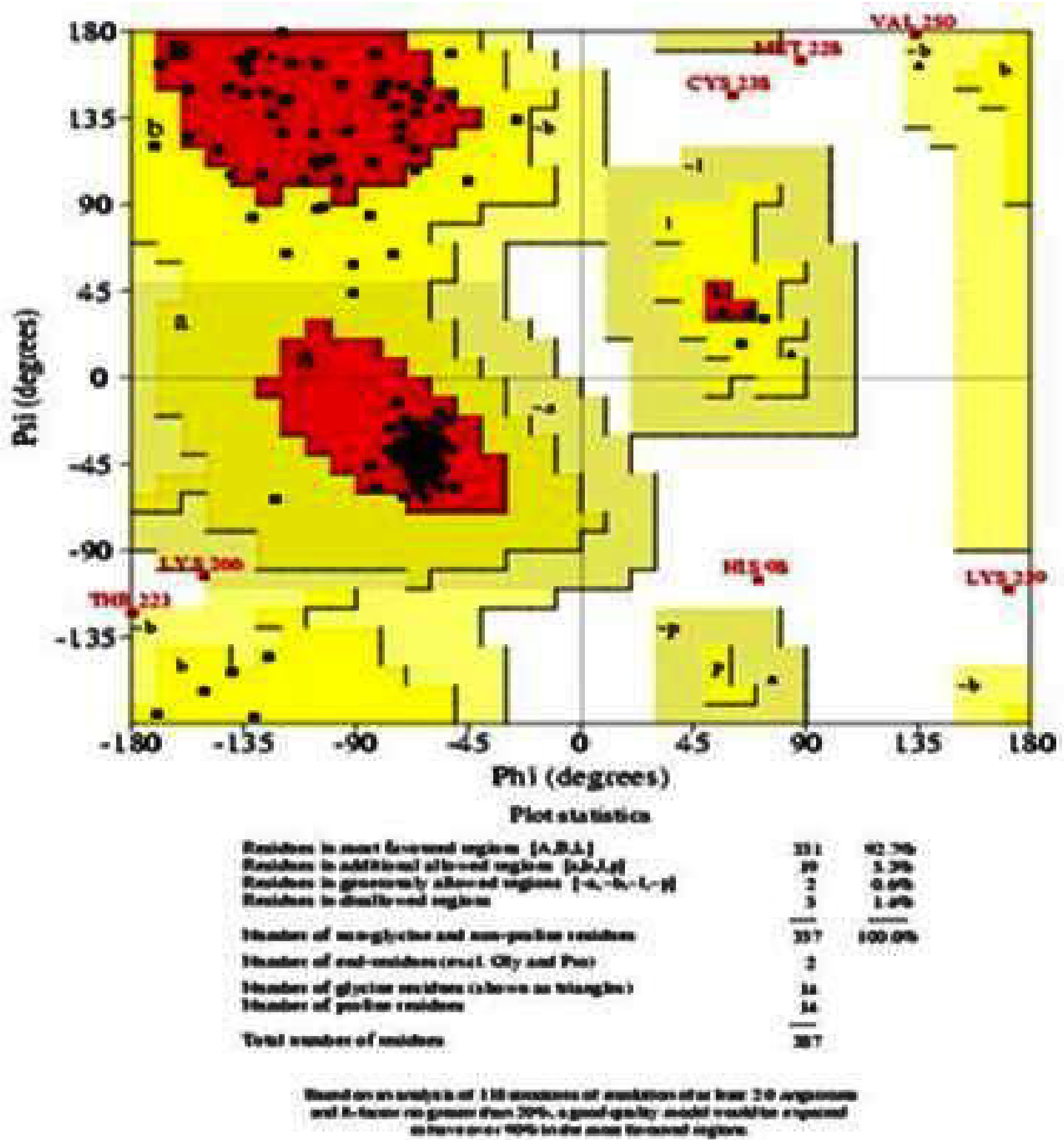

Figure 1: Ramachandran Plot of the selected best HTR2 model.

\section{Myristicin}

Myristicin is a known serotonin agonist, psychoactive drug, acting as an anticholinergic, and gets metabolised to 3-methoxy-4,5methylenedioxyamphetamine(MMDA). Also, it has a weak monoamine oxidase inhibitor action and with elemicin that gets metabolised to an amphetamine-like compound which has hallucinogenic effects [16,17].

Myristicin was loaded in the Maestro workspace. Phase hypothesis gave pharmacophore features of Myristicin as A1, A2, A3, H4, H5 and R6 (Figure 3).
This pharmacophore features matched with the compounds in Table 4.

The above compounds were docked with HTR2 receptor.

\section{Glide ligand docking}

Sitemap module was used to determine the binding site residues of the HTR2 receptor and as per the output sitemap_site_2 with SiteScore $1.004\left(2^{\text {nd }}\right.$ highest score $)$ and size 231 was used to determine the binding site of the modelled protein. 
Citation: Bagchi P, Venkatramana DK, Mahesh M, Somashekhar R, Kar A (2014) Identification of Novel Drug Leads for Receptors Implicated in Migraine from Traditional Ayurvedic Herbs Using in silico and in vitro Methods. J Neurol Disord 2: 185. doi:10.4172/2329-6895.1000185

Page 5 of 8

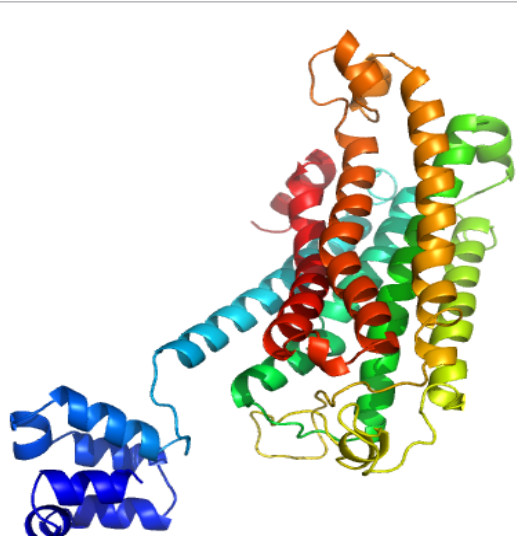

Figure 2: 3d Structure of the selected best HTR2 model.

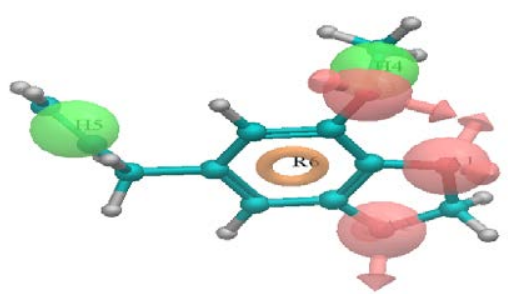

Figure 3: Pharmacophore features of Myristicin.

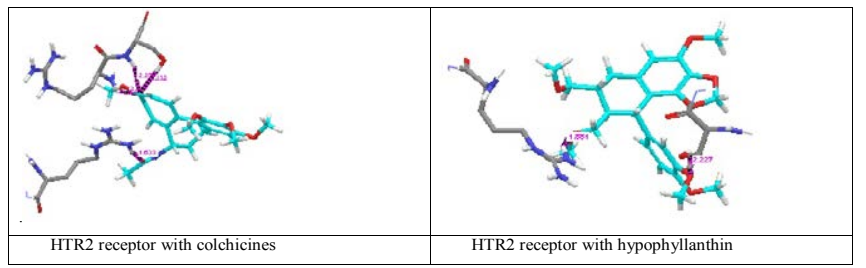

Figure 4: Docking results of HTR2 receptor with the colchicine and hypophyllanthin.

SER305, ALA306, CYS313, LYS316, PHE299, TYR303, VAL291, PRO293, ALA290, THR302, LEU298, ASN300, LYS320, GLU317, ASN376, ASP375, ALA372, LYS301, ASN318, ASP378, PRO321, TYR286, ILE174, TYR170, THR173, MET166, THR106, ARG89, LEU172, ILE168, THR169, MET166, THR106, PHE109, ILE165, ALA192, ALA195, ARG191, LYS107, LEU110, SER104.

The binding site region of the receptor was assigned and grid for the receptor was generated using Receptor Grid Generation module.

The HTR2 receptor was docked with colchicine and hypophyllanthin (Figure 4 and Table 5) $[18,19]$.

\section{ADME screening}

ADME is an acronym for absorption, distribution, metabolism, and excretion. QikProp is a quick, accurate, easy-to-use ADME prediction program designed by Professor William L. Jorgensen. QikProp predicts physically significant descriptors and pharmaceutically relevant properties of molecules [14].

\begin{tabular}{|l|c|c|c|c|}
\hline Ligand & $\begin{array}{c}\text { Docking scorel } \\
\text { glide g score }\end{array}$ & Doner & Distance in A & Interaction \\
\hline Colchicine & -7.191 & ARG388 & 2.207 & ARG388(OH)..O(UNK) \\
& & SER389 & 2.250 & SER389(OH)...(UNK) \\
& & ARG185 & 1.633 & ARG185(OH)..O(UNK) \\
\hline Hypophyllanthin & -6.303 & THR386 & 2.227 & THR386(OH)..O(UNK) \\
& & ARG393 & 1.881 & ARG393(OH)...(UNK) \\
\hline
\end{tabular}

Table 5: Docking results of HTR2 receptor with colchicine and hypophyllanthin [19].
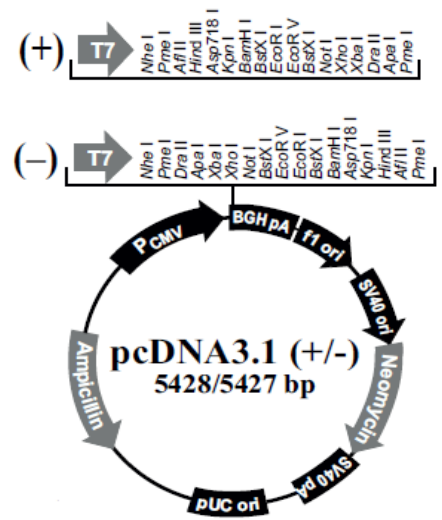

Figure 5: The figure summarizes the features of the pcDNA3.1(+) and pcDNA3.1(-) vectors. (@ invitrogen.

QikProp generated the following output (Tables 6 and 7) [19]:

\section{Receptor-ligand binding assay studies}

HEK cells were transfected with pcDNA3 containing HTR2 (Figures 5 and 6).

RT-PCR from total RNA isolated from stable cell line HEK- HTR2 confirmed the presence of HTR2 gene in the stable cell line. A band of $301 \mathrm{bp}$ was observed as expected (Figure 7).

Binding assay studies was done with HTR2 receptor with 5HT (known agonist for HTR2 receptor) [17], Colchicine and Hypophyllanthin using calcium assay buffer (Fluo-4 Direct reagent) [20].

Fluorometer reading at excitation at $494 \mathrm{~nm}$ and emission at 516 $\mathrm{nm}$ (done at Natural Remedies Pvt. Ltd., Bangalore, India) is given in Figure 8 and Table 8 .

\section{Conclusion}

Phytocompounds colchicine and hypophyllanthin binds to HTR2 receptor and exhibits activity. Colchicine exhibits maximum activity at $10 \mu \mathrm{m}$ concentration and hypophyllanthin exhibits maximum activity at $100 \mu \mathrm{m}$. Hence, the phytocompounds colchicine and hypophyllanthin proves agonists to HTR2 receptor and further in vivo and clinical trials should be done for establishing these as drugs for migraine and other neurological disorders.

\section{Future Perspective}

In this work the compounds colchicine and hypophyllanthin are already tested HTR2 agonist by in silico and in vitro methods. Currently 
Citation: Bagchi P, Venkatramana DK, Mahesh M, Somashekhar R, Kar A (2014) Identification of Novel Drug Leads for Receptors Implicated in Migraine from Traditional Ayurvedic Herbs Using in silico and in vitro Methods. J Neurol Disord 2: 185. doi:10.4172/2329-6895.1000185
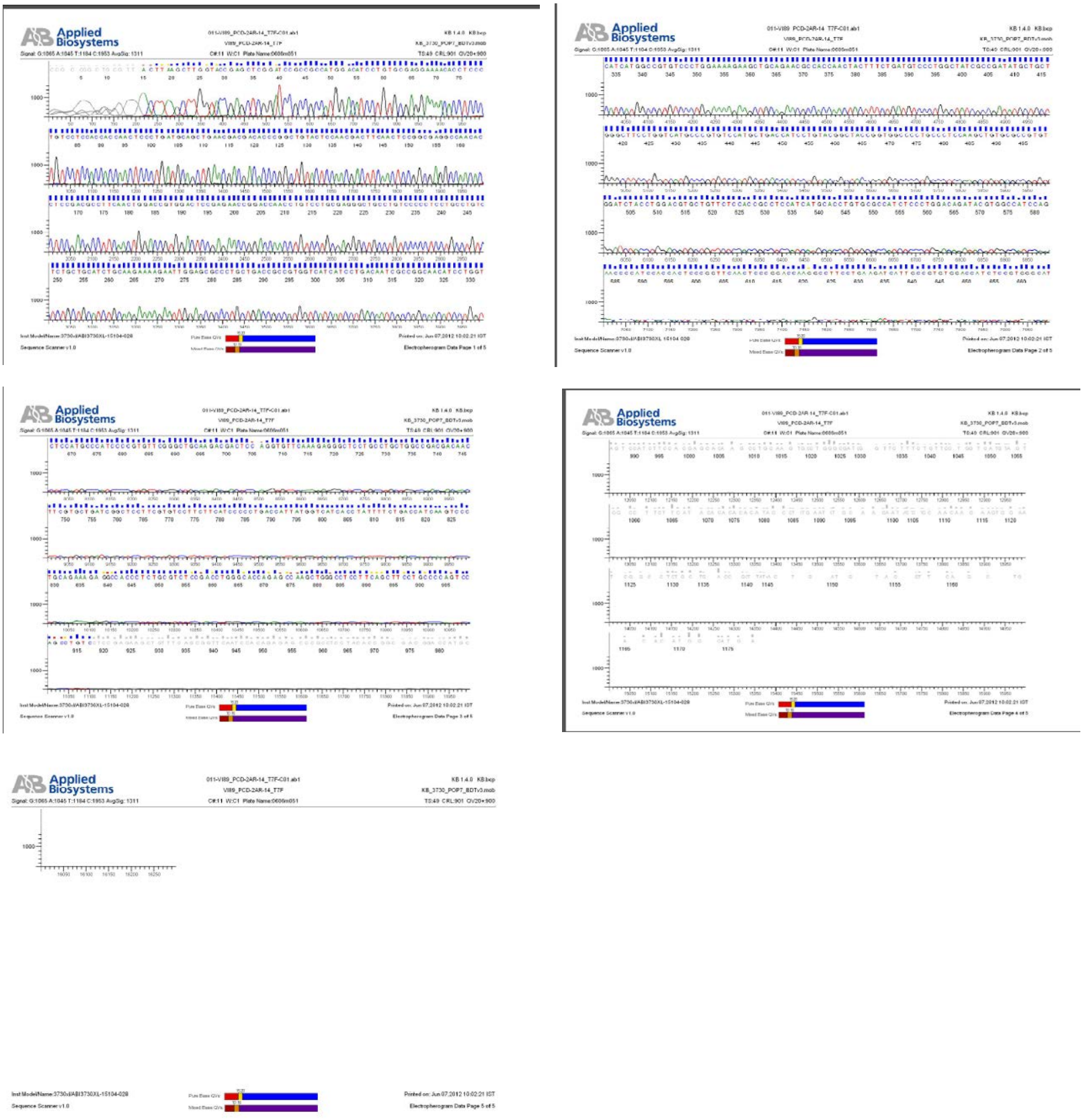

Figure 6: HEK DNA sequence $p$ containing cDNA3 of HTR2.

\begin{tabular}{|l|l|l|l|l|l|l|}
\hline Lead molecules & $\begin{array}{l}\text { Molecular weight } \\
\text { (g/mol) }\end{array}$ & $\begin{array}{l}\text { Molecular volume } \\
(\mathbf{A})\end{array}$ & PSA $^{\mathbf{c}}$ & HB $^{\mathbf{d}}$ donors & Rotatable bonds $^{\mathbf{f}}$ \\
\hline Colchicine & 399.443 & 1225.827 & 93.286 & 1.000 & 7.500 \\
\hline Hypophyllanthin & 430.497 & 1319.288 & 54.254 & 0.000 & 7.000 \\
\hline A $^{\star}$
\end{tabular}

$A^{*}$ indicates a violation of the $95 \%$ range.

a Molecular weight of the molecule.

'Total solvent-accessible volume in cubic angstroms using a probe with a radius of $1.4 \AA$.

'Van der Waals surface areas of polar nitrogen and oxygen atoms.

'Estimated number of hydrogen bonds that would be donated by the solute to water molecules in an aqueous solution. Values are averages taken over a number of configurations, so they can be non-integer.

e Estimated number of hydrogen bonds that would be accepted by the solute from water molecules in an aqueous solution. Values are averages taken over a number of configurations, so they can be non-integer.

${ }^{f}$ Number of rotatable bonds.

Table 6: Principal descriptors calculated by Qikprop simulation [19]. (Range 95\% of Drugs). 
Citation: Bagchi P, Venkatramana DK, Mahesh M, Somashekhar R, Kar A (2014) Identification of Novel Drug Leads for Receptors Implicated in Migraine from Traditional Ayurvedic Herbs Using in silico and in vitro Methods. J Neurol Disord 2: 185. doi:10.4172/2329-6895.1000185

Page 7 of 8

\begin{tabular}{|c|c|c|c|c|c|c|}
\hline Lead molecule & $Q P \log P(o / w)^{a}$ & $Q P \log S^{b}$ & QP PCacoc & QP log HERG ${ }^{d}$ & QP PMDCK & $\%$ Human oral absorption \\
\hline Colchicine & 2.545 & -3.809 & 550 & -3.180 & 483 & 91 \\
\hline Hypophyllanthin & 3.160 & -5.407 & 9906 & -4.994 & 5899 & 100 \\
\hline \multicolumn{7}{|c|}{ 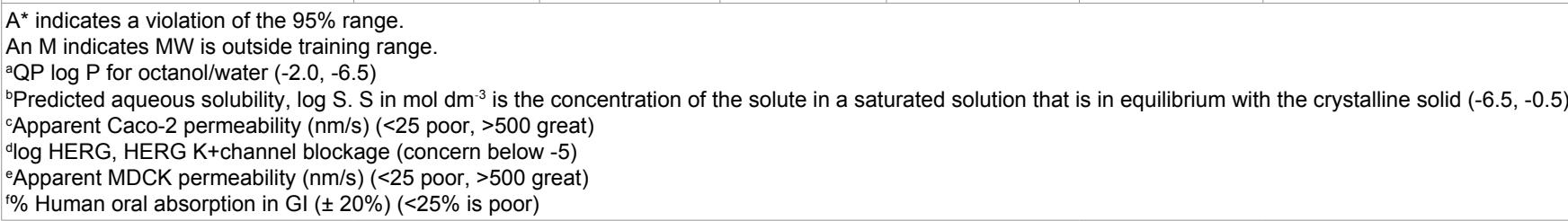 } \\
\hline
\end{tabular}

Table 7: Physiochemical descriptors calculated by Qikprop simulation [19]. (Range 95\% of Drugs).

\begin{tabular}{|c|c|c|c|}
\hline $0.00001 \mathrm{mM}$ & 0.142958252 & 0.10027043 \\
\hline $0.0001 \mathrm{mM}$ & 0.08932646 & 0.166483563 \\
\hline $0.001 \mathrm{mM}$ & 0.233351644 & 0.068463196 \\
\hline $0.01 \mathrm{mM}$ & 0.2227140201 & 0.073174596 \\
\hline $0.1 \mathrm{mM}$ & 0.158761514 & 0.373278121 & 0.148440801 \\
\hline $1 \mathrm{mM}$ & 0.133704471 & 0.068494887 & 0.067015972 \\
\hline & $5 \mathrm{HT}$ & Colchicine & 0.0903936787 \\
\hline
\end{tabular}

Table 8: Fluorometer reading of HTR2 receptor with ligands at different concentrations at excitation at $494 \mathrm{~nm}$ and emission at $516 \mathrm{~nm}$.

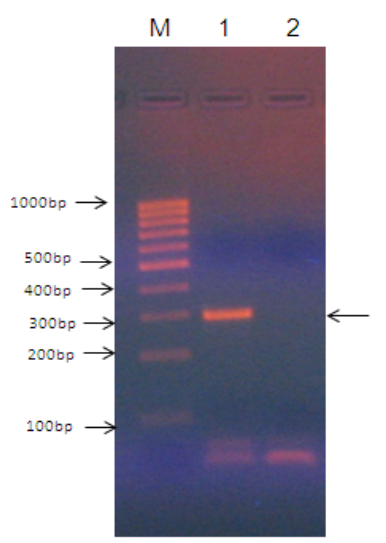

M-100bp DNAladder; 1- HEK-5HT2AR Stable cell line; 2- HEK 293 Expected size of PCR product is $301 \mathrm{bp}$

Figure 7: RT-PCR to check for expression of HTR2 gene in stable cell line.

there is no animal model for migraine. Based on the present results, the authors would develop an animal model to test the compounds colchicine and hypophyllanthin to test in vivo.

\section{Acknowledgement}

1) In silico work was performed at Department of Bioinformatics, SRM

University, Chennai, India - which is being gratefully acknowledged.

2) Natural Remedies Pvt. Ltd., Bangalore, India.

\section{References}

1. Olson EJ, Boeve BF, Silber MH (2000) Rapid eye movement sleep behaviour disorder: demographic, clinical and laboratory findings in 93 cases. Brain 123 : 331-339.

2. Boeve BF, Silber MH, Saper CB, Ferman TJ, Dickson DW, et al. (2007) Pathophysiology of REM sleep behaviour disorder and relevance to neurodegenerative disease. Brain, 130: 2770-2788.

3. van de Ven RC, Kaja S, Plomp JJ, Frants RR, van den Maagdenberg AM, et al (2007) Genetic models of migraine. Arch Neurol 64: 643-646.

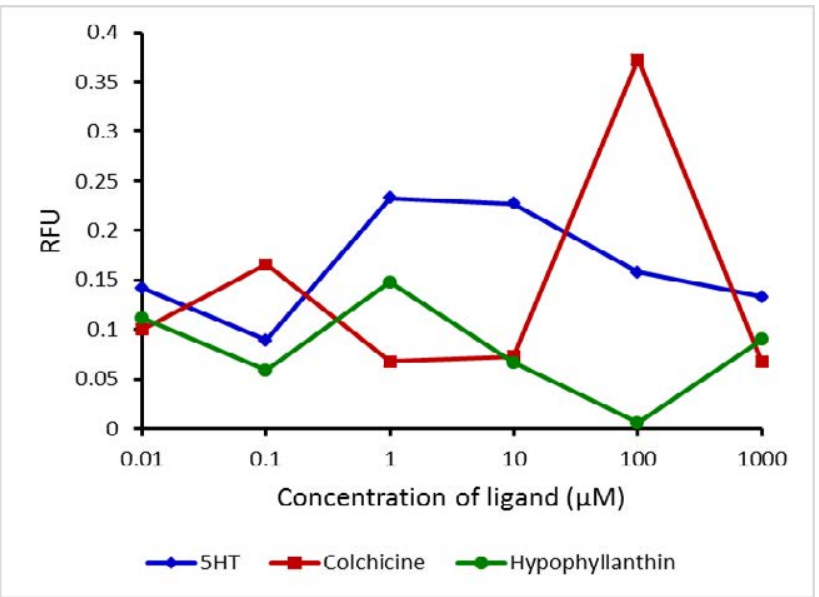

Figure 8: Calcium response to HTR2 receptor ligands (5HT agonist). Cells were stimulated with selected ligands. Measurements are given in fluorescent units (RFU) as maximum response minus the minimum response divided by the minimum response. Rank order ligand potency agreed with published results [20].

4. Hamel E (2007) Serotonin and migraine: biology and clinical implications Cephalalgia 27: 1293-1300

5. Bécamel C, Gavarini S, Chanrion B, Alonso G, Galéotti N, et al. (2004) The serotonin 5-HT2A and 5-HT2C receptors interact with specific sets of PDZ proteins. J Biol Chem 279: 20257-20266.

6. Roth BL, Willins DL, Kristiansen K, Kroeze WK (1998) 5-Hydroxytryptamine2family receptors (5-hydroxytryptamine2A, 5-hydroxytryptamine2B, 5-hydroxytryptamine2C): where structure meets function. Pharmacol Ther 79 : 231-257.

7. Van Oekelen D, Luyten WH, Leysen JE (2003) 5-HT2A and 5-HT2C receptors and their atypical regulation properties. Life Sci 72: 2429-2449.

8. Choi MJ, Lee $\mathrm{HJ}$, Lee $\mathrm{HJ}$, Ham BJ, Cha JH, et al. (2004) Association between major depressive disorder and the $-1438 \mathrm{~A} / \mathrm{G}$ polymorphism of the serotonin $2 \mathrm{~A}$ receptor gene. Neuropsychobiology 49: 38-41.

9. Steele TD, McCann UD, Ricaurte GA (1994) 3,4-Methylenedioxymethamphetamine (MDMA, "Ecstasy"): pharmacology and toxicology in animals and humans. Addiction 89: 539-551. 
Citation: Bagchi P, Venkatramana DK, Mahesh M, Somashekhar R, Kar A (2014) Identification of Novel Drug Leads for Receptors Implicated in Migraine from Traditional Ayurvedic Herbs Using in silico and in vitro Methods. J Neurol Disord 2: 185. doi:10.4172/2329-6895.1000185

Page 8 of 8

10. Zheng GG, Kenney PM, Lam LKT (1992) Myristicin: a potential cancer chemopreventive agent from parsley leaf oil. J Agric Food Chem 40: 107-110.

11. Shulgin AT (1966) Possible implication of myristicin as a psychotropic substance. Nature 210: 380-384.

12. Sali A, Blundell TL (1993) Comparative protein modelling by satisfaction of spatial restraints. J Mol Biol 234: 779-815.

13. Laskoswki RA, MacArthur MW, Moss DS, Thorton JM (1993) PROCHECK: a program to check the stereochemical quality of protein structures. J Appl Cryst 26: 283-291.

14. Schrödinger Suite (2010) Protein Preparation Guide, SiteMap 2.4; Glide version 5.6, LigPrep 2.4, QikProp 3.3, Schrödinger, LLC, New York, NY.

15. Taha MO, Dahabiyeh LA, Bustanji Y, Zalloum H, Saleh S, (2008) Combining Ligand-Based Pharmacophore Modeling, Quantitative Structure-Activity
Relationship Analysis and in Silico Screening for the Discovery of New Potent Hormone Sensitive Lipase Inhibitors. J Med Chem 51: 6478-6494.

16. Truitt EB Jr (1967) The pharmacology of myristicin and nutmeg Psychopharmacol Bull 4: 14

17. Sonavane GS, Sarveiya VP, Kasture VS, Kasture SB (2002) Anxiogenic activity of Myristica fragrans seeds. Pharmacol Biochem Behav 71: 239-244.

18. Demetriades AK, Wallman PD, McGuiness A, Gavalas MC (2005) Low cost high risk: accidental nutmeg intoxication. Emerg Med J 22: 223-225.

19. Singh KhD, Kirubakaran P, Nagarajan S, Sakkiah S, Muthusamy K, et al (2012) Homology modeling, molecular dynamics, e-pharmacophore mapping and docking study of Chikungunya virus nsP2 protease. J Mol Model 18: 39-51.

20. Fluo-4 DirectTM Calcium Assay Kits @2009, Molecular Probes. 